\title{
Literature Review on Credit Risk of China's P2P Lending
}

\author{
He Feiyang $^{1}$ \\ ${ }^{1}$ School of Business, Nanjing Normal University, China \\ Correspondence: He Feiyang, School of Business, Nanjing Normal University, China. E-mail: \\ hefeiyang1011@gmail.com \\ Received: January 15, 2020 \\ Accepted: March 26, 2020 \\ Online Published: April 14, 2020 \\ doi:10.5539/ijbm.v15n5p55 \\ URL: https://doi.org/10.5539/ijbm.v15n5p55
}

\begin{abstract}
P2P lending develops fast in China and many scholars have done research on it. I explore the credit risk of China's P2P lending by gathering and classifying essays. To be specific, I discuss the classification of credit risk and empirical research on it. Then I analyze the problems in P2P lending in China and how to control them, which is significant for investors and supervisors. Although China's P2P lending platforms run badly in 2019, several platforms are under transformation. Other platforms can draw lessons from transformation.
\end{abstract}

Keywords: P2P lending, classification of credit risk, risk management, transformation

\section{Introduction}

Peer-to-Peer (P2P) lending meets the new trend of financial de-intermediation, and has developed rapidly both at home and abroad. The $\mathrm{P} 2 \mathrm{P}$ lending systems in other countries are gradually improving due to their mature credit information system and market supervision mechanism. In contrast, the quality of China's P2P online lending platforms varies widely and there is evident polarization in terms of development with a high ratio of problematic platforms as well as frequent illegal fundraisings and unpredictable shutdowns. For example, the case of Ezubao in 2016 seriously threatened the sound development of online lending industry in China. China's P2P lending can provide funds for many small and micro businesses and individuals that are blocked from commercial banks, improve the efficiency of private capital, and promote the marketization of private capital. It is an additional and essential part of the development of China's lending finance. From the perspective of investors, online lending is a high-yield investment method; while for borrowers, online lending is an efficient option. Hence, researches on China's P2P lending can provide investors with a unique angle of views to identify the quality of different platforms, which contributes to the improvement of online lending policies and regulatory systems.

Given credit risk being the main risk of China's P2P lending, this article, as a literature review, summarizes the empirical researches on credit risk and identification of China's online lending by Chinese scholars.

\section{Classification of Credit Risks in Online Lending}

The traditional lending market has a mature credit risk management system where the amount and interest rate of the loan subject are determined based on the borrower's collateral and credit rating. The traditional ways of borrowing often include the third party's periodic review of the borrower to ensure the borrower's ability to repay. Therefore, the credit risk of the traditional lending market can be well controlled. However, the lack of strong third-party's financial support and supervision in online lending has resulted in a slightly different classification of credit risks from that of the traditional lending. Quan Ying (2018) believes that the credit risks of P2P lending can by classified according to different default subjects. There are three main bodies of conventional P2P lending: lenders (investors), borrowers and online platforms. From the lenders' perspective, they deposit their spare funds into the platform with the intention of investment and financial management. The possibility of default is less likely to happen and the credit risk is small. From the borrowers' perspective, due to the asymmetric information, the borrowers who hope to obtain funds may selectively hide part of their credit information. This also exposes borrowers to larger risks owing to the imperfection of the online lending review process. In addition, Li Yan et al. (2014) believe that the description of borrower's information will affect the investor's decision, and that the soft information of the borrowers correlates with the default rate of online lending (Jiang Cuiqing et al., 2017). Therefore, the borrower's credit risk is large and can be examined from multiple dimensions. In terms of the online lending platforms, the faultiness existing in their supervision systems has caused huge credit risks. According to the statistics of WDZJ, an authoritative P2P online loan industry portal in China, there were 50 P2P 
platforms nationwide before 2012, among which 10 were problematic platforms, accounting for $20 \%$ of the total. By the end of 2014, there were 1,843 platforms across the country in total, of which 387 were problematic platforms, making up 21\% (He Guanghui, 2017). The problematic P2P lending platforms usually raise funds by using fictitious subjects to build pools of capital and repay old debts by borrowing new debts. One of the typical cases for such an act is the Ezubao incident in 2016.

\section{Empirical Researches on Risk Identification of Online Lending}

\subsection{Description of Basic Authentication Information}

P2P lending platforms will require borrowers to disclose their basic credit information, including credit ratings, income levels, ownership of property, existing debts, debt-to-income ratios and so on. The credit information revealed by a borrower will be reviewed and rated by a third-party credit rating agency. The description of borrowing information has an impact on the success rate and borrowing cost. Peng Hongfeng (2016) empirically analyzed the impact of loan descriptions on the success and the actual rate of borrowing before and after the changes in the interest rate mechanism, using transaction data on the online lending platform from December 2007 to February 2012 as a sample. The analysis found that compared with the fixed model of borrowing rate, borrowers with lower credit ratings in the mode of interest rate auction were more inclined to provide loan descriptions. Under both models of interest rate, the statements provided by borrowers could reduce the cost of borrowing, but not necessarily increase the success rate. Studies abroad have shown that (Klafft, 2008) the borrower's credit rating plays a crucial role in the success of the loan, and it is generally given by the rating agency with hard and soft information. The additional loan descriptions provided by borrowers with low credit ratings can make up for the lack of objective information and reduce the degree of information asymmetry in borrowing. In respect of risk identification, when the borrower provides a description of the loan, it should be noted that the borrower may have a low credit rating and large credit risk.

\subsection{Risk Identification is Not Reflected by Irrational Regional Discrimination}

Regional discrimination in traditional lending markets usually stems from information asymmetry in different regions. On the online lending platform, the borrowers and lenders do not need to have a face-to-face contact, and the information can spread quickly through the network. Therefore, online lending can intuitively reduce geographical discrimination. However, the empirical analysis of Chinese scholar Liao Li (2014) found that after controlling the information of orders and borrowers, there are still significant regional differences in the success rate of orders between the provinces, indicating that there is regional discrimination in the transactions of the $\mathrm{P} 2 \mathrm{P}$ lending platforms. However, through further researches, the default rate of orders in discriminated provinces is not significantly higher than that in non-discriminated provinces, manifesting that such discrimination is irrational. Therefore, the geographical factors cannot be given excessively high risk weights on P2P lending platforms. Geographical discrimination in online lending is true, but its existence is more likely to be caused by the cultural and economic differences among regions instead of different loan default rates.

\subsection{Education of Borrowers}

The traditional lending market attaches great importance to the educational levels of borrowers. For example, education is a very important indicator in the personal credit rating system of China's commercial banks. In the online lending market, scholar Liao Li (2015) conducted an empirical analysis of academic qualifications and loan default rates. He collected the data of Renrendai, a representative company in China's P2P online lending, to study the impact of education on credit recognition process of the personal lending, further investigating whether the online lending market can accurately identify the value of academic qualifications. The study found that concerning the results of default, the default rate of high-education lenders is lower, indicating that high-education strengthens the self-discipline of borrowers. For the investors, they do not reveal their preference for highly educated borrowers. There is a deviation in identifying the behaviors with credit risks. Hence, from the perspective of investor decision-making, high education can become a standard for credit risk identification. However, in the practice of online lending, well-educated borrowers are not significantly favored to others. The reason of such a phenomenon deserves scholars' further investigation.

\subsection{Gender}

Gender bias in financial affairs was first proposed by Gary Becker (1957). The emerging online lending has facilitated the communication between investors and lenders and provided massive amounts of public data. Foreign scholar Schafer studied the data from Smava, a German P2P lending platform. The results showed that there is no "sexual discrimination" in German online lending platforms. Domestic scholars Hu Feng and Chen Yuyu (2012) pointed out in their research on rural household's loan lending that female heads of households are 
less likely to obtain loans from formal financial institutions and prefer to borrow through informal financial institutions. Xinhua Dou and other scholars (2018) have empirically studied gender discrimination on online lending platforms by using the data on Renrendai in China, and found that there is significant heterogeneity in the risk propensity of gender. Women tend to have a lower probability of default than men, but also less likely to have successful borrowing. This indicates female borrowers have suffered more serious irrational gender discrimination in China's P2P lending market.

The existence of irrational gender discrimination in online lending process shapes the deviation in investors' credit risk identification. Therefore, avoiding irrational gender discrimination plays an important role in improving the efficiency of online lending funds as well as the risk identification ability of investors.

\section{Control of Credit Risks}

\subsection{Problems in Credit Risk Control of Traditional P2P Lending Platforms}

At present, traditional P2P platforms mainly exist issues as follows: First, information asymmetry leads to insufficient accuracy of risk assessment. In order to control risks, online lending platforms usually increase the entry threshold for borrowing and select users with better credit, thereby avoiding the risk of default or bad debts. However, there exists a few borrowers who have good credit but fail to meet some of the standards have been abandoned due to the lack of comprehensive analysis and data understanding of borrowers. Although the bad debt rate of the platform could be reduced in this way, it will also shrink a large part of the potential benefits. Thus, this method of credit risk management is imperfect. Second, static assessment tools fail to adapt to changes in borrowers' credit risk information. The traditional static assessment tool means being in a static state after the relevant information of the borrower has been collected and risk analyzed, which cannot adapt to the dynamic changes of the borrowers. On the one hand, the credit situation of borrowers may worsen, so it is of high credit risk to continue to lend to such borrowers. On the other hand, some borrowers with high credit risk may improve their repayment ability and the refusal to lend them will cause potential losses.

\subsection{Exploration of Credit Risk Control Mechanism}

At present, online lending platforms mainly rely on the collection of hard information from borrowers for related risks and credit evaluation. To solve those problems above, the online lending platform can take the following steps:

First, integrate various credit information systems on different platforms to achieve sharing information. The credit information system is the primary source of information for P2P lending platforms. On the one hand, it depends on the credit data accumulated by various platforms in all kinds of businesses, while on the other hand, it relies on the sharing of credit information between platforms. To prevent and control the credit risks, apart from continuing the development of Internet financial risk information sharing system and further accelerating the credit sharing between P2P platforms, it is also necessary to establish related incentive mechanisms, such as calculating the input costs of a platform at preliminary phrase and providing relevant preferential policies to attract more platforms into the sharing system. In addition, the standardization of credit systems is particularly important in a gesture to improve the efficiency of data sharing. China's credit reporting industry is in its infancy. If the content and format of credit information collected via P2P lending platforms can be unified, it will greatly facilitate the overall construction of the online lending credit system. Second, strengthen the cooperation with credit reporting agencies as a third party to improve the credit evaluation capability. The involvement of external credit reporting agencies can standardize the development of online lending industry. With the established credit evaluation systems on each platform, the participation of the third-party agencies can enrich the sources of credit information, which helps to comprehensively screen and figure out effective variables that can judge individual credit levels. Continuous update of the analysis system as well as well-constructed real-time data analysis models can provide a basis for investors to make reasonable investment decisions. Third, implement a differentiated approach to regulation. Differentiated regulatory approaches refers to adopting differentiable means to supervise institutions of different importance, development time and scales. In the early stage of China's online lending platforms, the adherence to one type of regulation may stifle the impetus for financial innovation, but a loose regulatory environment will undermine the development environment of the online lending industry. Therefore, there should be some focuses in the supervision of credit risk existing in P2P lending platforms. Those institutions that have the potential of causing nationwide systemic risks should be carefully monitored. For those nascent online lending platforms, they should adhere to the basic rules of risk supervision and avoid making themselves bear excessive pressure. 


\section{Conclusion and Transformation}

This article summarizes 22 literatures, analyzes and sorts out the classification, identification and control of credit risk in P2P lending. With the development of Internet finance, P2P lending platforms have improved the efficiency of private capitals, provided new channels for private loans, and complemented the traditional financial lending business. Nevertheless, this also comes with a series of development problems, especially the imperfection of credit reporting system of the online lending platforms, which conceals many credit problems and poses a great challenge to the credit risk control. The Internet finance and online lending industries also urgently need to establish relevant regulatory mechanisms to ensure and regulate the sound and sustainable development of P2P lending, thus providing borrowers with broader and fairer financing channels, and guaranteeing investors' decisions.

On the other hand, P2P platforms are also actively seeking transformation. Paipai Loan and Renren Loan has transformed successfully. For Paipai Loan, on November 7, 2019, Paipai Loan announced that it was renamed "Xinye Technology" and transformed into a FinTech company. One month before the name was changed, Paipai Loan no longer issued new bids for lenders, and all funds came from institutions. The person in charge of Xinye Technology said that in the next half year, Xinye Technology will achieve the orderly clearing of P2P business.

The reason for the Paipai Loan transformation is on the one hand the regulatory pressure of Internet finance, and on the other hand the need to improve its development platform. There are two sufficient conditions for the successful transformation of Paipai loan. First, there was research and development activities in the early stages of the development of financial technology systems. According to its own user data, Paipia Loan has developed a magic mirror system that can automatically evaluate the risk of the subject, and has been successfully used. Due to the large proportion of the R\&D sector in the development plan of Paipai Loan, Paipai Loan can be smoothly transformed. Secondly, Paipai Loan has sufficient cash flow. According to the financial report, since 2016, Paipai Loan has achieved profit. In the three years to 2018, the net profits of Paipai Loans reached 501.5 million yuan, 10.829 billion yuan and 2.469 billion yuan, respectively. A total of 1.962 billion yuan. On November 21, when the third quarter financial report was released, the cash and short-term working capital of Paipai Loan was approximately RMB 2.2 billion. Since the R \& D project itself is characterized by large initial investment and high return in the later period, sufficient cash flow can support the transformation of the auction loan.

The other is about Renren Loan. From the perspective of development strategy, the transformation of Renren Loan has actually been implicit in the three major development strategies issued by the company. It can be known from its official website that the three major development strategies of Renren Loan are as follows: First, Renren Loan completes the compliance filing requirements, and the platform adheres to compliance operations. Second, the platform realizes the transformation and upgrade from P2P platform to technology financial platform. Since its establishment, Renren Loan has accumulated relevant data and risk control capabilities in the field of micro-credit, and the platform is currently actively trying to transform and upgrade to the fintech sector. Third, the platform serves more potential investors through Internet technology.From a technical perspective, Renren Loan has reviewed and approved the Group Technical Committee system management measures, which will play an active role in corporate technology planning and scientific research results. It can be seen that Renren Loan has gradually transitioned into becoming a technology financial company.

From the perspective of the company's financial situation, Renren Loan has achieved profitability for four consecutive years since 2016. As of 2018, its net profit has reached 98.9955 million yuan. The company's financial status is healthy, and major online loan rating websites have given high ratings. It can be seen that Renren Loan is the leading company in online loan platforms. Only in 2019, Renxin Financial's Youxin Financial Services fintech-related projects won four awards: Youxin Financial won the "Top 50 Fintech", Youxin Financial's risk control platform won the "2019 Leading Science and Technology Outstanding Project", Renren Loan won the "Excellent Technology Financial Service Platform" and Youxin Financial Services received the "Product Innovation Award of the Year", which shows that Renren Loan's R\&D capabilities are outstanding.

\section{References}

Berger S. C., \& Gleisner, F. (2009). Emergence of Financial Intermediaries in Electronic Market: The Case of Online P2P Lending. Business Research, 2(1), 39-65. http://doi.org/10.1007/bf03343528

Ceyhan, S., Shi, X., \& Leskovec, J. (2011). Dynamic of Bidding in a P2P Lending Service. Effects of Herding and Predicting Loan Success. Proceeding of the 20th International Conference on World Wide Web, 547-556. http://10.1145/1963405.1963483

Freedman, S., \& Jin, G. Z. (2008). Do Social Networks Solve Information Problems for Peer-to-Peer Lending? 
Evidence from Prosper.com. Working Papers, College Park, MD: NET Institute. http://doi.org/10.2139/ssrn.1936057

He, G. H., Yang, X. Y., \& Pu, J. J. (2017). Risks and Their Determinants of P2P Internet Lending Platforms in China. The Journal of Quantitative \& Technical Economics, (11), 44-62. http://doi.org/10.13653/j.cnki.jqte.2017.11.003

Jensen, M., \& Meckling, W. H. (1976). Theory of the Firm: Managerial Behavior, Agency Costs, and Ownership Structure. Journal of Financial Economics, 3(4), 305-360. http://10.1007/978-94-009-9257-38

Liao, L., \& Zhang, W. Q. (2017). Empirical Research on Online P2P Lending: A Literature Review. Journal of Tsinghua University (Philosophy and Social Sciences, (2), 186-197. http://doi.org/10.13613/j.cnki.qhdz.002580

Liao, L., Ji, L., \& Zhang, W. Q. (2015). Education and Credit: Evidence from P2P Lending Platform. Journal of Financial Research, (3), 146-159.http://doi.org/10.13613/j.cnki.jqte.2015.03.003

Liao, L., Li, M. R., \& Wang, Z. W. (2014). Regional Discrimination in Chinese Internet Finance. The Journal of Quantitative \& Technical Economics, (5), 54-70. http://doi.org/10.13653/j.cnki.jqte. 2014.05.004

Peng, H.F., Zhao, H. Y., \& Zhou, Y. (2016). Could the loan Description Affect the Loan Cost an Loan Success Rate? Textual Analysis Based on the Loan Description. Journal of Financial Research, (4), 158-173. http://doi.org/10.14086/j.cnki.wujss.2016.04.009

\section{Copyrights}

Copyright for this article is retained by the author(s), with first publication rights granted to the journal.

This is an open-access article distributed under the terms and conditions of the Creative Commons Attribution license (http://creativecommons.org/licenses/by/4.0/). 